\title{
Reaction of Azodioxide with Thianthrene Cation Radical
}

\author{
Kyung-Hee Cho and Wang Keun Lee
Chemistrv Education Major. Facultu of Science Education, Chonnam National Chiversin. Guangin 500-757, Korea
${ }^{*}$ E-mail: wkeeia chonnamac.kr
Received March 2, 2007

Key Words : Azodioxide. Thianthrene cation radical. Thermal decay

We recently reported on the thiantlurene cation radical perchlorate $\left(\mathrm{Th}^{-} \mathrm{ClO}_{4}^{-}\right)$induced oxidative decomposition of carbonates (eq 1). ${ }^{l}$ carbamates (eq 2). ${ }^{2}$ azodicarbosylate (eq 3 ) ${ }^{3}$ dicarbonate (eq 4). ${ }^{+}$peroxides (eq 5 ). ${ }^{5}$ and disulfide (eq $6)^{6}$ where $\mathrm{R}$ in equations is tert-butyl. In each of these reactions. electron-transfer-mediated C.N C.O or C.S bond cleavage was found. Substantial bond weakening was shown to accompany the tert-butyl cation due to the electron loss from these substrates.

In a continuation of our work on $N N^{\prime}$-dioxoazobis(2methyl-2-propane) (1) in acetonitrile solution at room temperature $\mathrm{C}, \mathrm{N}$ and $\mathrm{N} . \mathrm{O}$ cleavages. followed by addition

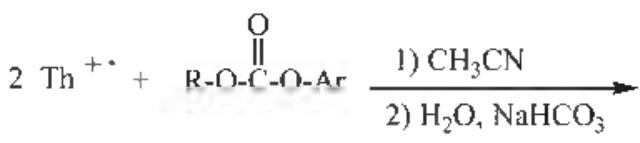

$$
\begin{aligned}
& \mathrm{RNHCOCH}_{3}+\mathrm{Th}+\mathrm{Th}^{+}-\mathrm{Ar}-\mathrm{OH}+\mathrm{CO}_{2} \\
& 2 \mathrm{Th}^{+*}+\text { R-O-C-NR'-Ar } \frac{\prod_{1} \text { 1) } \mathrm{CH}_{3} \mathrm{CN}}{\text { 2) } \mathrm{H}_{2} \mathrm{O}, \mathrm{NaHCO}_{3}} \\
& \mathrm{RNHCOCH}_{3}+\mathrm{Th}+\mathrm{Th}^{+}-\mathrm{Ar}-\mathrm{NHR}{ }^{\prime}+\mathrm{CO}_{2}
\end{aligned}
$$

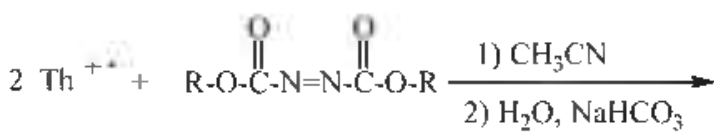

$$
\begin{aligned}
& 2 \mathrm{RNHCOCH}_{3}+2 \mathrm{Th}+\mathrm{N}_{2}+2 \mathrm{CO}_{2}
\end{aligned}
$$

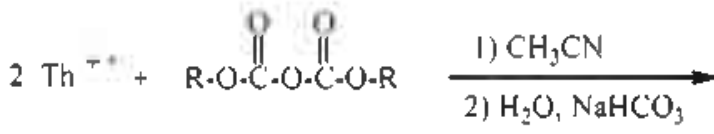

$$
\begin{aligned}
& 2 \mathrm{RNHCOCH}_{3}+2 \mathrm{Th}+\mathrm{ThO}+2 \mathrm{CO}_{2} \\
& 2 \mathrm{Th}^{+}+\mathrm{R}-\mathrm{O}-\mathrm{O}-\mathrm{R} \frac{\text { 1) } \mathrm{CH}_{3} \mathrm{CN}}{\text { 2) } \mathrm{H}_{2} \mathrm{O}, \mathrm{NaHCO}_{3}} \\
& 2 \mathrm{RNHCOCH}_{3}+\mathrm{Th}+\mathrm{ThO}+\mathrm{SSO}_{2} \\
& 2 \mathrm{Th}^{+\cdot}+\text { R-S.S.R } \frac{1) \mathrm{CH}_{3} \mathrm{CN}}{2) \mathrm{H}_{2} \mathrm{O}_{4} \mathrm{NaHCO}_{3}} \\
& 2 \mathrm{RNHCOCH}_{3}+2 \mathrm{Th}+\mathrm{R} \cdot \mathrm{S} \cdot \mathrm{S} \cdot \mathrm{S} \cdot \mathrm{S} \cdot \mathrm{R}+\mathrm{S}_{2}
\end{aligned}
$$

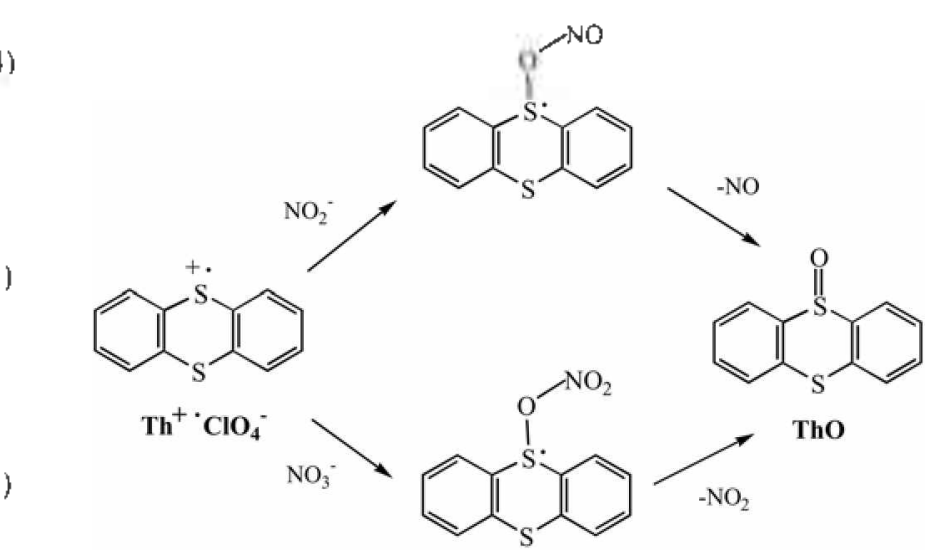

Scheme 1

of $\mathrm{Th}^{-} \mathrm{ClO}_{4}^{-}$to azodioxide. 1 . was found to give thianthrene oxide (ThO) and $\mathrm{N}$ - -butylacetamide (3), with evolution of nitrogen gas. Reactions of $\mathrm{Th}^{-} \mathrm{ClO}_{4}^{-}$with anions. such as nitrite and nitrate ions. have been reported. ${ }^{7}$ but its reactions with molecules with an abnormal number of bonds have not been documented. This work affords the first example of the addition of a cation radical to formal negatively charged oxygen within a neutral molecule.

Reactions of nitrite and nitrate ions with $\mathrm{Th}^{-} \mathrm{ClO}_{4}^{-}$were found to give thiantlurene 5-oxide (ThO) quantitatively (Scheme 1). Reactions with ${ }^{18} \mathrm{O}$-labeled nitrite and nitrate ions showed that the oxygen in $\mathrm{ThO}$ came from the nitrite and nitrate ions respectively.

In the present study. as with the other oxidative decom$\mathrm{Th}^{+} \mathrm{ClO}_{4}^{-}$are also characteristic of tert-butyl cations. which imply carbocationic chemistry is predominantly observed from a nitrosoalkane dimer. The products obtained were $\mathrm{N}-\mathrm{i}$ butylacetamide (3). ThO and $\mathrm{N}_{2}$ as detenmined by quantitative GC and GC/MS analyses. $N$-i-butylacetanide (3) from the tert-butyl cation, which was isolated in a yield of $91 \%$ and $\mathrm{ThO}(76 \%)$ was obtained by oxygen transfer from 1. Without doubt. 3 arose from hydration, during workup. of a Ritter-type intermediate $\left(\mathrm{Me}_{3} \mathrm{CN}={ }^{-} \mathrm{CMe}\right)$ from the reaction of $\mathrm{Me}_{3} \mathrm{C}^{-}$with the MeCN solvent. Accordingly. all reactions were carried out with a $2: 1$ stoichiometry of the cation radical and 1 . Generally, in the reaction of thianthrene cation radical perchlorate. $\mathrm{ThO}$ is obtained as a side product from the hydrolysis of $\mathrm{Th}^{-} \mathrm{ClO}_{4}^{-}$by water. either adventitiously in the solvent or added during workup. ${ }^{8}$ However, in this position. ${ }^{1-6}$ the major products from the reaction of 1 with 


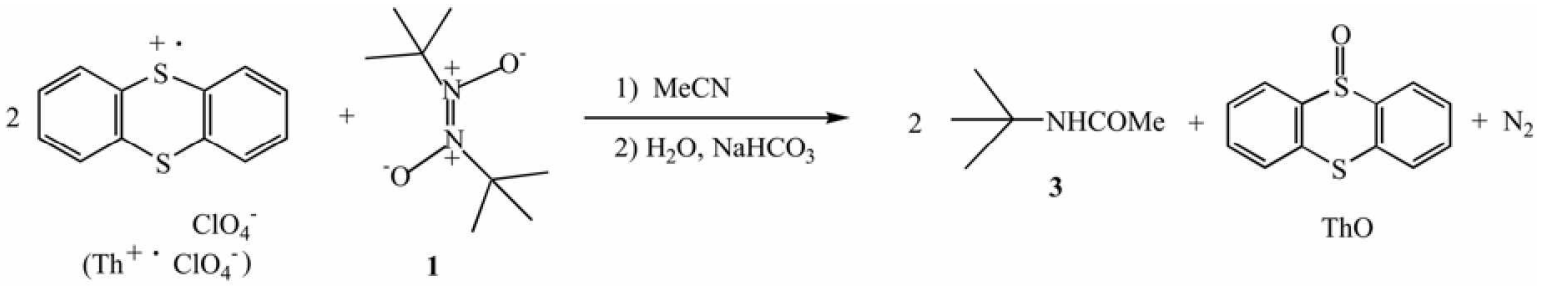

Scheme 2

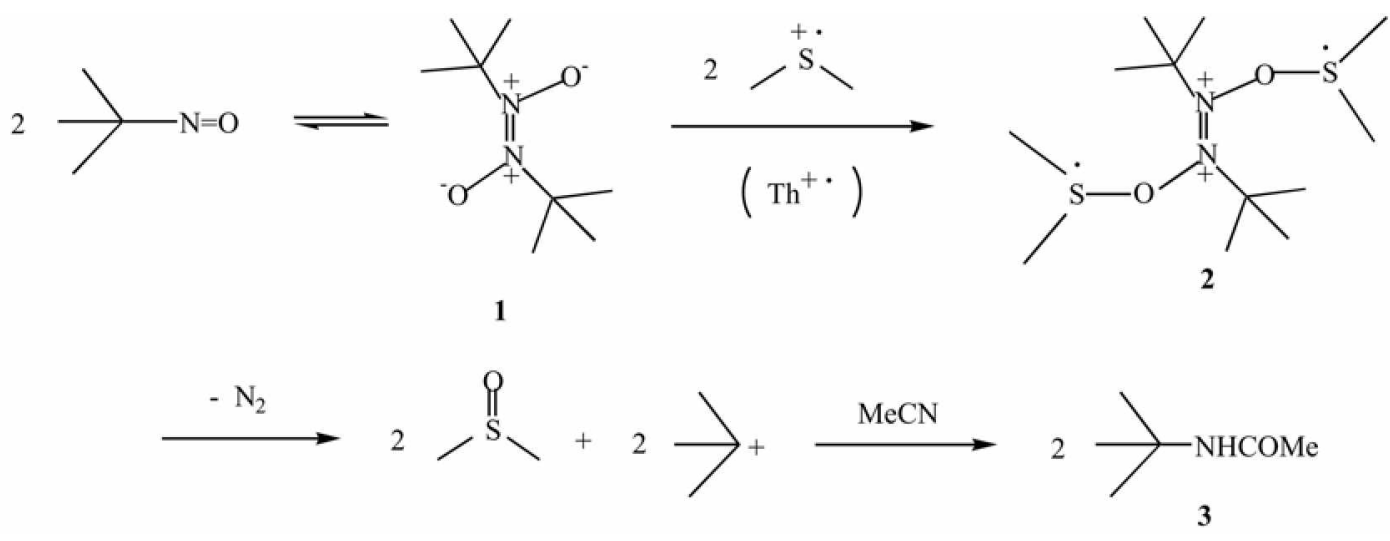

Scheme 3

reaction. the ThO was the primary product rather than a side product. This result suggests that the oxygen atom in ThO comes entirely form 1 . The formation of $\mathrm{ThO}$, by oxygen transfer from the nucleophiles. as a primary product has been previously reported from the reactions of nitrite and nitrate ions, ${ }^{7}$ oximes, ${ }^{9} \mathrm{cyclic}$ alcohol, ${ }^{10}$ and 2,3-dimethyl-2,3butanediol ${ }^{\mathrm{jl}}$ with $\mathrm{Th}^{-} \mathrm{ClO}_{4}^{-}$.

Products obtained from the reaction of $\mathrm{Th}^{+} \mathrm{ClO}_{4}{ }^{-}$with 1 are shown in Scheme 2, and an explanation for the formation of products is shown in Scheme 3. Azodioxide (1). as in Scheme 3. equilibrates with the 2-methyl-2-nitrosopropane monomer. Because the rate of approach to equilibrium in solution between dimer (1) and monomer is moderately slow (30-60 min) at room temperature and very slow at low temperature. ${ }^{12}$ it is possible to prepare and maintain nonequilibrium solutions of the pure dimer (1). Scheme 3 shows that the nucleophile. the negatively charged oxygen of 1 . at a high negative charge density attacks the thianthrene ring at the sulfur (the 5 position). An intemediate cation radical (2) is formed. which can decompose into a stable product. ThO and 3. with evolution of $\mathrm{N}_{2}$. The order of initial bond cleavages either $\mathrm{N} . \mathrm{O}$ or $\mathrm{C}, \mathrm{N}$ in the cation radical intermediate. 2 currently remains unknown. The reaction of 1 with $\mathrm{Th}^{-} \mathrm{ClO}_{4}^{-}$is somewhat unlike the analogous reactions with tert-butyl containing compounds, such as carbonates. carbamates azodicarboxylate dicarbonate. peroxides and disulfide. These lead to electron-transfer-mediated oxidative decomposition. In contrast. 1 is first added to $\mathrm{Tl}^{+} \mathrm{ClO}_{4}^{-}$, which thereafter decomposes into stable products.

In conclusion. the first example of cation radical-induced themal decay of stable azodioxide (1) is reported. In the reaction of 1 with a cation radical is quite unlike the analogous reactions described in eq. (1-6). From this reaction, themal decay rather than electron-transfer-mediated bond cleavage. follows the addition of 1 to the cation radical.

\section{References and Notes}

1. Park. Y. S.: Lee. W. K. Bull. Korean Chem. Soc. 1997. 18. 360.

2. Choi. I. M.: Ma. E.-K.: Soln. C. K.: Lee. W. K. Bull. Korean Chent Soc. 2000. 21. 1254.

3. Park, Y. S. Han, D. S.; Lee, W. K. Bull. Korean Chem. Soc 1998. 19.615 .

4. Chung. J. H.: Lim. S. H.; Solnn, C. K.: Lee. W. K. Bull. Koran Chent Sac. 1998. 19.792.

5. Park. B. K.: Sohn1. C. K.: Lee W. K. Bull. Korem Chem. Soc. 2002. 23. 103.

6. Park, B. K.: Lee. W. K. Bull Koman Chem. Soc 2003, 24. 655

7. Shine, H. J.: Silber, J. J.: Bussey, R. J.; Ohuyama, T. J. Org. Chem. 1972. 17,2691

8. Shine. H. J.: Murata. Y. J. Org. Chent 1969. 34.3368.

9. Chiou. S.: Hque. A. K. M. M.: Shine. H. J. J. Org. Chent 1990. 55.327.

10. Shine, H. J: Yueh. W. J. Org. Chem. 1994, 59.3553

11. Han. D. S.: Shine. H. J. J. Org. Chem. 1996. 61, 3997.

12. Greer. M. L.: Sarker, H.; Mendicino. M. E.: Blackstock, S. C. $d$. An. Chem. Soc. 1995. 117. 10460. 